Allen Buchanan

\title{
The Open-ended Normativity of the Ethical
}

\begin{abstract}
In The Ethical Project, Kitcher has three main aim: (1) to provide a naturalistic explanation of the rise of morality and of its subsequent development, (2) to supply an account of moral progress that explains progressive developments that have occurred so far and shows how further progress is possible, and (3) to propose a further progressive development - the emergence of a cosmopolitan morality - and make the case that it is a natural extension of the ethical project. I argue that Kitcher does not succeed in achieving any of these aims and that he cannot do so given the meager resources of his explanatory model. The chief difficulty is that Kitcher equivocates in his characterization of the original (and still supposedly primary) function of ethics. Although he begins by characterizing it as (a) remedying altruism failures in order to avoid their social costs, he sometimes characterizes it instead as (b) remedying altruism failures simpliciter. Kitcher does not explain how a practice whose original function was (a) developed into one whose function is (b). Further, it appears that he cannot do so without significantly enriching his explanatory model to include a more robust account of how humans came to have the capacity to reflect on and revise norms.
\end{abstract}

\section{Introduction}

The Ethical Project is an admirable intellectual achievement and at the same time a masterful exhibition of skill in communication. Kitcher realizes the idea of a public intellectual: He is able to present complex ideas and arguments to a broad audience and to do so without loss of accuracy or rigor. In what follows I will be critical of The Ethical Project, but I am convinced that this book will stimulate fruitful discussion and set a high standard for future efforts to understand morality.

Kitcher's aims in The Ethical Project are admirably - indeed, breathtakingly-ambitious. First, he seeks to provide an historical explanation of what morality is and of how it has developed over time. Second, he aims to supply an account of moral progress that will provide a principled basis both for our assumptions about which changes in the past have been progressive and for the belief that further progress is possible. Third, he tries to use his account of morality and moral progress to ground a proposal for a new progressive development, the creation of a genuinely cosmopolitan morality. I shall argue that none of these three goals is achieved and that none of them can be achieved, given the limited resources that Kitcher provides for understanding morality. 


\section{The Historical Account of Morality and Its Development}

The potential value in Kitcher's historical approach to explaining morality derives from the strategy of explaining how humans could have engaged in some pre-ethical activity that gave rise to ethics. In other words, his history must begin with something non-moral to explain morality, for if he began with an activity that is already within the domain of morality, then he could not give a full historical explanation of morality. That something is the first employment of the capacity for normative guidance (Kitcher's technical-sounding term for rulefollowing) to solve a particular practical problem. The problem, which he says our ancestors shared with chimps and bonobos, was that altruism failures were common and resulted in serious social costs. Altruism failures are cases where individuals do not act toward one another as psychological altruists would act: They do not adjust their behavior toward one another in ways that reflect a willingness of each to attempt to ensure that the other's desires are satisfied. The notion of being responsive to the desires of others here is susceptible of a stronger and weaker interpretation: on the stronger interpretation it means that each gives equal weight to the desires of all affected in a particular interaction, including his own; on the weaker interpretation a psychological altruist is someone who gives weight to the desires of all, but not necessarily equal weight. Surprisingly, Kitcher does not distinguish the stronger and weaker interpretations, and in consequence it is not altogether clear what counts as an altruism failure. On the stronger interpretation of what it is to perform as a psychological altruist, then altruism failures are only avoided when all individuals give equal weight to the satisfaction of the desires of all.

Unfortunately, Kitcher systematically equivocates in characterizing the starting point of the ethics: Although he begins his account by describing it as (i) our ancestors' using their capacity for normative guidance to remedy altruism failures that result in serious social costs $(E P, 67 ; 73 ; 222 ; 409),{ }^{1}$ when it comes to explaining how morality developed and what counts as progress in its development, he relies instead on the quite different description of it as (ii) our ancestors' using their capacity for normative guidance to remedy altruism failures simpliciter. There is a corresponding equivocation in his characterization of the original function of ethics: Sometimes he says it is to remedy altruism failures that result in serious costs, sometimes he says it is to remedy altruism failures. The difference between these characterizations is this: According to the first, avoiding social costs is the ultimate function, and remedying altruism failures is a function only so far as it contributes to that; according to the second, the ultimate function is to remedy altruism failures, regardless of whether doing so is the best way to avoid their social costs. That these are two different functions becomes clear, once we see that in some circumstances, the best way

\footnotetext{
1 Kitcher variously describes the consequences of altruism failures as social friction, social friction and violence, and the tearing of the social fabric along with time-consuming and stressful efforts to mend it. I use the term 'social costs' to cover all of these related notions.
} 
to avoid the social costs of altruism failures may not be to remedy them, but instead to avoid their social costs in some other way.

The difference between these two characterizations of the original function of ethics comes out quite clearly in Kitcher's explanation of why the development of repressive elite rule after a supposed period of primitive egalitarianism was not a progressive development in morality. He says that such a social arrangement is not even within the bounds of the ethical project because it only treats the symptoms of altruism failures without remedying the altruism failures themselves $(E P, 225-29 ; 274)$. The symptoms are social costs - tensions and conflicts and the energy expended in coping with them - that arise from the failures of altruism. The idea is that a ruler or ruling elite could use the fear of coercion to avoid the social costs of altruism failures without remedying the altruism failures themselves by imposing severe penalties on those whose exhibit disruptive behavior when their desires are disregarded. At this point the reader will understandably ask: If ethical norms first arose as a way of avoiding the social costs associated with altruism failures, then why say that the original function of ethics was to remedy altruism failures rather than to reduce social costs? Kitcher might reply that characterizing the original function as remedying altruism failures to reduce their social costs is more informative, given that there are other sources of social costs and other ways of reducing them. But then a question remains: How did remedying altruism failures simpliciter, rather than remedying altruism failures only insofar as doing this most effectively reduces the social costs to which they give rise become the function of the project of developing normative guidance? How did the ultimate function of ethics become remedying altruism failures simpliciter rather than avoiding social costs? Why would the use of normative guidance to avoid the social costs of altruism failures without remedying the failures themselves - treating the symptoms rather than the causes - not also count as part of the ethical project, if the mechanism employed in both cases was the creation and social embedding of norms? And why would humans develop a practice of remedying altruism failures simpliciter, regardless of whether this was the best way or the only way to avoid the costs of altruism failures?

It is crucial to understand that Kitcher operates with a very demanding characterization of what it is to remedy an altruism failure: It is for the relevant individuals to be behaviorally altruistic toward all whose desires or interests are at stake in an interaction, to act as they would act if they were thorough-going psychological altruists - agents who appropriately adjust their own desires in response to the desires of others and in a way that "[. . . acknowledges the wishes and aspirations of all members of society" $(E P, 274)$. This characterization is compatible with both the stronger and the weaker interpretation of what it is to avoid an altruism failure, because acknowledging the wishes and aspiration of all is compatible with giving them either equal weight or not, but presumably it does require that everyone's wishes and aspirations be given some weight. It is because he is operating with this demanding conception of remedying altruism failures and proceeding on the assumption that the function of the ethical project is to remedy altruism failures thus understood that he concludes that reducing 
the social costs of altruism failures by instituting repressive elite rule-only treating the symptoms of altruism failures, rather than remedying the failuresdoes not even count as part of the ethical project, much less as a progressive development within it. For this conclusion about repressive rule to make sense, the defining function of the ethical project must not be avoiding the social costs of altruism failures; it must instead be avoiding altruism failures simpliciter. However, a commitment to avoiding altruism failures simpliciter, where this means developing a set of norms that 'acknowledges the wishes and aspirations of all' as something pursued for its own sake rather than being pursued only in so far as this is the best way to avoid serious social costs, looks awfully like a moral commitment. The worry is that Kitcher is operating with a moralized understanding of what it is to remedy altruism failures.

The virtue of Kitcher's first characterization of the original function of ethics, in which the ultimate function is the avoidance of social costs and remedying altruism failures is only a function so far as it contributes to that, is that it allows him to start with a non-moral motivation: the simple desire to avoid social costs. If instead, he begins with the desire to remedy altruism failures simpliciter, where this means the desire to acknowledge the desires and wishes of all as something valued for its own sake, rather than merely so far as it reduces social costs, then the strategy collapses: He is explaining morality by showing how it arose out of a moral motivation, the motivation to acknowledge the wishes and aspirations of all as something valued on its own account. What Kitcher needs to do if the strategy of explaining morality historically by elucidating its non-moral origins is to succeed, but what he does not do, is to show how an activity whose original function was to remedy altruism failures only insofar as this reduced social costs became transformed into one whose function was to remedy altruism failures simpliciter. He is faced, then, with a dilemma: Either he must stick with the strategy of explaining how morality could arise from something nonmoral and then provide an explanation of how the function of avoiding costs by remedying altruism failures gave rise to the function of remedying altruism failures simpliciter (regardless of whether this is the best way to avoid the social costs); or he must abandon his primary aim and acknowledge that he is not providing an historical explanation of morality, but instead explain how a richer morality could have developed from a morality whose function was limited to remedying altruism failures simpliciter, understood in the moralizing way (rather than remedying them only so far as this fulfilled the function of reducing the social costs to which they give rise). If he takes the latter path he must, of course, still explain why humans became preoccupied with remedying altruism failures simpliciter rather than remedying them when this happened to be the best way to avoid their costs.

I have suggested that the commitment to remedying altruism failures, where this means acting so as to acknowledge the wishes and aspirations of all, is a moral commitment, but my main criticism of Kitcher's account of the rise of morality does not rely on that being the case. Even if his account does not violate the stricture of explaining the rise of the moral by reference to something nonmoral, the central problem remains: He has not explained how reliance on 
norms that function to avoid social costs by remedying altruism failures could have given rise to norms that function to remedy altruism failures simpliciter.

In section 3, I substantiate my claim that Kitcher does not provide such an explanation and, in section 4, I will show why his failure to do so undermines his claim that a genuinely cosmopolitan morality can develop out of the realization of the original function of the ethical project. For now, I want to explain why Kitcher shifts from characterizing the function of ethics as remedying altruism failures that result in serious social costs to characterizing it as remedying altruism failures simpliciter. The key to my explanation is a very specific (and controversial) assumption Kitcher makes about the circumstances in which the ethical project began.

Kitcher asserts that the ethical project began in a condition of equality, more specifically, equality of threat advantage $(E P, 11)$. He surmises that norms could become established only if all the adult members of early human societies assented to them, because the welfare of the group depended on the cooperation of every adult member. ${ }^{2}$ By virtue of having the capacity to make credible threats not to cooperate, each adult member in effect possessed a veto. Accordingly, in this original condition of equality, the feasible means of using our normative capacity to reduce the costs of altruism failures were tightly constrained: Only those norms that acknowledged "the wishes and aspirations of all" could become accepted $(E P, 274,295)$. In other words, in those circumstances, reducing the social costs of altruism failures and remedying altruism failures simpliciter were functionally equivalent - the costs of altruism failures could only be avoided by remedying the altruism failures, not by other means, such as repressing or ignoring the desires of some members of the community. In these conditions, the only way to avoid the costs of altruism failures was to remedy the failures, not merely treat their symptoms.

The problem for Kitcher is that, as he admits, we are no longer in those circumstances: The supposed original equality has given way to extreme inequality. But if that is so, then the question arises: If the original ultimate concern was to avoid the serious social costs arising from altruism failures (not to remedy altruism failures simpliciter), why did humans continue to remedy the failures rather than avoid the costs in other ways (that is, committed to treating the cause, rather than the symptoms). One answer might be that sometime after we began developing norms to remedy altruism failures (when that was the only effective way to avoid their costs, in the circumstance of equality), two things happened: We found ourselves in inegalitarian circumstances in which the option of avoiding the costs of altruism failures without remedying the failures

\footnotetext{
2 Kitcher's egalitarianism assumption is problematic, because he does take seriously the possibility that equality in early human groups was limited to males. There is, after all, considerable evidence that in some persisting premodern groups women are relegated to an inferior position in important ways (for example, as regards control over sexual activity and access to food). See note 3 below. Quite apart from that, Kitcher is too quick to assume that all adults (or even all males) could credibly threaten noncooperation. Less powerful or less skilled members of the group were arguably more dependent on the group for survival than the group was dependent on them (especially in circumstances where groups were widely scattered and safe entry into and acceptance by another group was not very probable).
} 
themselves arose, and we somehow developed a capacity for normative reasoning that resulted in our seeing that remedying altruism failures, rather than just avoiding their costs in other ways, was itself valuable. In other words, we came to appreciate the value of ways of avoiding the costs of altruism failures that acknowledged the wishes and aspirations of all members of society as such, not just because and when this was the only effective way to avoid social costs.

One can at least begin to imagine how this change might have occurred, if one acknowledges what might be called the open-ended normativity of the ethical. The idea would be that human beings have the capacity to reflect on the norms they follow and to reason about them in ways that lead them to acknowledge new norms - including norms that that express a commitment to the value of each individual human being (or at least each member of one's society), irrespective of their threat capacity or other strategic properties. This way of proceeding, however, runs directly contrary to a major thesis of Kitcher's book, namely, that the original function of ethics remains its primary function $(E P, 8)$. For as I have argued, the original function of ethics, according to what Kitcher should say if he wishes to explain the moral in terms of non-moral origins, is to remedy altruism failures so far as they have serious social costs, not to remedy altruism failures simpliciter.

Appealing to the development of our capacity for normative reasoning is not the only way one might explain why the ethical project is directed toward remedying altruism failures simpliciter, long after the demise of the equality of threat capacity that made this the only effective way of avoiding the social costs of altruism failures. One might instead propose a cultural-selectionist argument to show why, even in circumstances of inequality, societies that developed norms that remedied altruism failures in Kitcher's moralized sense, by acknowledging the wishes and aspirations of all, rather than avoiding their costs in other ways, were favored. In other words, one might argue that suppression of what might be called legitimate desires tends to have results that are counterproductive, in terms of the features of societies that are the targets of cultural selection. Unfortunately, Kitcher does not supply either type of explanation. He does not explain how human societies developed norms and practices for remedying altruism failures simpliciter rather than for remedying them only in circumstances in which that is the best way of reducing the social costs they produce. He does not explain how, in the conditions of inequality that he admits have obtained for thousands of years, social norms would arise and become embedded whose ultimate function is to reduce the social costs of altruism failures by acknowledging the wishes and aspirations of all.

My surmise is that Kitcher does not provide such an explanation because he does not sufficiently appreciate the implications of his original equality assumption. On his own account, it is a constraint that focuses the ethical project on remedying altruism failures rather than treating their symptoms, but once the constraint is lifted, he gives us no reason to think that the focus on remedies would remain. To put the same point differently, Kitcher does not explain why the function of the ethical project under the peculiar and fleeting contingency of equal threat capacity would persist as its function under quite different cir- 
cumstances. To be true to the aim of giving a full historical explanation of morality, on that begins with something nonmoral, Kitcher should unequivocally say that the ethical project began as humans harnessed their capacity for normative guidance to the task of avoiding serious social costs, including and perhaps even primarily those costs that result from altruism failures. But that way of proceeding would not lead, without more argument than he provides, to the conclusion that the primary function of the ethical project today and through all of its history after the initial period of equality is to remedy altruism failures.

My assessment of Kitcher's execution of his first aim - to provide an explanation of the origin and subsequent development of morality - can now be briefly summarized. He has not given a historical explanation of morality that starts with something nonmoral. If he sticks with the notion that the original function of the ethical project happened to be to remedy altruism failures because, due to the contingent and temporary fact that threat capacity was equal, the only way to avoid the social costs of altruism failures was to remedy the failures, then he must then admit that he has not explained why remedying altruism failures (rather than remedying them only when this is the only or the best way to avoid the associated social costs) is the primary function of ethics in the present (or any function at all, for that matter). This first alternative enables him to honor his commitment to providing a nonmoral starting point for his explanation of morality, but undercuts his ability to provide the explanation. Alternatively, if he admits that the function with which his account begins is that of remedying altruism failures simpliciter - understood in a moralized way as acknowledging the wishes and aspirations of all (rather than doing so simply because equality of threat capacity makes this the only way to avoid the costs of altruism failures) - then he must abandon his claim to have given a full explanation of morality, because he will have explained morality in terms of a moral commitment-and one whose existence remains utterly mysterious on his view.

Before turning to his account of moral progress, I want to note that my criticism so far has granted Kitcher the assumption that the ethical project originated in circumstances of equality. That assumption is much more problematic than Kitcher acknowledges. Kitcher, like many others, bases his characterization of early human societies on evidence about contemporary premodern societies (along with speculations about similarities between early humans and chimps). However, there is considerable evidence that not a few contemporary premodern societies exhibit considerable inequality between men and women. ${ }^{3}$ If early societies exhibited similar gender inequality, then Kitcher will have given us no good reason to conclude that the solution to the problem of social costs resulting from altruism failures was as tightly constrained as he says: We cannot assume that the norms that developed to solve this problem had to acknowledge the wishes and aspirations of all members of society. Quite apart from the fact that

\footnotetext{
${ }^{3}$ For a small sample of the large literature documenting gender inequality in pre-modern societies, see the following: Edgerton 1992, 74-105; Herdt 1998, 347-350. Kim Sterelny provides an evolutionary explanation of how practices of extreme inequality could arise and become stable: Sterelny 2007.
} 
Kitcher's generalization about the egalitarian character of early human societies seems to have overlooked the evidence of gender inequality, there is another problem: Some members of society - for example, especially ferocious warriors or exceptionally successful hunters - may have been regarded as sufficiently more valuable to the group that the threat of their non-cooperating weighed more heavily. On Kitcher's view, this would mean that they could exert more influence on the character of the norms that became accepted, presumably in ways that gave more weight to their interests. If this occurred, then the norms might not acknowledge the wishes and aspirations of all members of the group, or at least would not give them anything like equal weight. If, as Kitcher says, the ethical project only began when humans harnessed their capacity for normative guidance to remedy altruism failures in the sense of developing responses to conflicts of interest that acknowledged the wishes and aspirations of all, then it is hard to see how it would ever get off the ground if there was either gender inequality or significant inequality as to how the cooperation of different individuals affected group welfare. Having said that, I wish to emphasize that my first criticism of Kitcher shows that his primary explanatory aim is not achievable, even if we grant him the assumption that early human societies were egalitarian.

\section{The Account of Moral Progress}

There are two main difficulties with Kitcher's treatment of moral progress. The first is that he does not explain how what he takes to be progressive changes developed out of the supposedly original function of remedying altruism failures, even if we grant his characterization of what it is to remedy an altruism failure (as involving norms that acknowledge the wishes and aspirations of all members of society). The second is that he not only omits consideration of what may be one of the most momentous developments in our understanding of morality, but also appears to be barred from making sense of it by his account of the egalitarian circumstances in which the ethical project began.

Kitcher lists several progressive developments in the ethical project: the abolition of chattel slavery, the recognition of the equal rights of women, the transition from viewing same sex preferences and behavior as vicious to viewing them as on a par with heterosexual preferences and behavior and subject to the same criteria of moral appraisal, and the emergence of punishment practices that reflect a clearer recognition of individual responsibility. Yet in none of these cases does he provide an account of how these transitions could have occurred that actually makes use of the idea that the original function of the ethical project was to remedy altruism failures. The closest he comes is in the case of the recognition of women's equal rights. There he notes that an important first step was to convince large numbers of the public that women - normal women - actually desired a much broader range of opportunities. There is some connection here to Kitcher's moralized notion of remedying altruism failures, because this first step involved coming to acknowledge some 'wishes and aspirations' that had before been overlooked. But that is a far cry from providing an explanation of how the 
original function of remedying altruism failures could have developed in such a way as to produce the progressive development of the recognition of women's equal rights. For one thing, we are given no clue as to how the discharging of the original function could have led to socially-embedded ways of determining priorities among the wishes and aspirations of different groups in cases in which they are in conflict, in this instance women, on the one hand, and traditional men, on the other. The answer cannot be that discharging the original function could only be achieved by a resolution of this conflict of interest that was fair, because the solution had to be acceptable to all. That answer might suffice in the original condition of equality, because norms could not become socially embedded there unless they were acceptable to all. But the circumstances in which the equal rights of women were first asserted were circumstances of gross inequality.

The difficulty here is the yawning gap between the notion of remedying altruism failures - even in its moralized form - and the complexities of moral reasoning about conflicts of interests. In fact, it is not much of an exaggeration to say that any serious consideration of moral reasoning and its role in moral progress is conspicuously absent in The Ethical Project. Instead, Kitcher remains content to emphasize that new ethical practices do not come about through moments of insight prompted in the way in which scientific progress occurs and to appeal to the idea that new desires become 'acknowledged'.

It is hard to see how Kitcher's characterization of the function of ethics could explain moral progress. There is an indefinitely large range of possible norms all of which acknowledge the wishes and aspirations of all in society, ranging from those that give equal weight to the desires or interests of all to extremely inegalitarian ones. All of these norms fulfill the function of remedying altruism failures on KItcher's understanding of what counts as a remedy. But what that shows is that the hypothesis that the original and still primary function of morality is to remedy altruism failures tells us very little about morality or moral progress. What we need, but do not get from Kitcher, is an account of how humans developed better ways of adjudicating recurring conflicts of interests, not just by creating and implementing norms, but also by learning to reason about norms in ways that allow them to see that some ways of responding to conflicts of interests are preferable to others.

Of course, the assumption that progressive transitions had much to do with the development of moral reasoning can be challenged. On some accounts, it is shifts in power that matter and moral reasoning is only ad hoc window-dressing. Kitcher does not avail himself of that sort of approach, however, and to do so would be at odds with his emphasis on the ethical project's reliance on norms. Nor does he provide a mixed account that delineates the interaction of power as it is ordinarily understood and the power of normative reasoning. In the other cases of moral progress Kitcher discusses, the problem is if anything worse: His view about the original (and still supposedly primary) function of ethics simply does not explain how these transitions came about. At most we get vague references to how the pursuit of the original function gave rise to new desires and new ways of remedying the altruism failures that they occasioned. In sum, Kitcher's 
discussions of instances of moral progress, while perceptive and interesting, float free from his explanatory model.

Moreover, it is puzzling that Kitcher does not even attempt to explain one other transition that many of us believe was highly progressive: the abandonment (by some of us at least) of the idea that the ultimate sanction of morality is an unseen enforcer, God or providence or the mandate of heaven, etc. He explains how belief in an unseen enforcer provided a powerful boost to the social sanctions attached to norms that helped remedy altruism failures, but offers no explanation of how new attempts to remedy altruism failures could lead to the abandonment of the idea of an unseen enforcer.

Presumably, the explanation of how at least some people have come to abandon the notion that there is an unseen enforcer of morality would have to refer to developments beyond the boundaries of the ethical project as Kitcher conceives it: the rise of modern science and with it the availability of naturalistic explanations for phenomena that were previously thought to be explainable only by supernatural causes; the loss of the Catholic church's monopoly on Christianity in the West and the subsequent proliferation of religious views, including Protestant varieties that gave more credit to the individual's own judgment as to how to live, the rise of new norms of behavior centered on the market and in some cases in direct opposition to religious teachings, and so on. Kitcher does not explicitly say that the development of the ethical project can understood without reference to forces exogenous to it, but he proceeds as if that were the case. $^{4}$ It is highly controversial, however, to assume that the development of ethics is self-sufficient in this way.

A related progressive development - and one that J. B. Schneewind characterizes as a revolution rather than a reform - is the idea that morality is about happiness, not about what is forbidden or required by tradition or according to some sacred text (Schneewind 1996). Schneewind identifies Bentham as the figure who crystallized this revolutionary idea. Kitcher is silent on how his understanding of the ethical project illuminates this progressive transition as well.

\footnotetext{
${ }^{4}$ Perhaps Kitcher does not think he needs to explain the rejection of the idea of an unseen enforcer, because he does not view it as an instance of moral progress. His conception of moral progress is functional: Developments are progressive insofar as they enable human ethical practices better to perform the function of remedying altruism failures (and the new functions to which this gives rise). The falsity of the belief in an unforeseen enforcer is irrelevant to its functional efficacy. On this view, it is not clear how the rejection of the belief in an unseen enforcer or of the belief that what is moral depends on what God wills could be understood to be progressive. For after all, it might turn out that in this case false belief is more functionally efficacious than true belief. At this point, one may wonder whether something has gone seriously wrong in Kitcher's account of moral progress. A purely functional account of progress - where the function is remedying altruism failures, irrespective of whether the means of doing so involves radically false understandings of what ethics itself is about-seems inadequate. One would think that an ethical practice that is not grounded in that sort of falsehood is more progressive, other things being equal, than one that is. To put the same point differently, if one sticks to his purely functional conception of progress, an ethical practice that included the participants' acceptance of Kitcher's naturalistic account of how ethics arose and developed would not be more progressive than one founded on the false belief that moral rules are God's commands.
} 
A much more serious omission in Kitcher's discussion of moral progress is the repudiation of what I have called morality as self-interested reciprocity, a view about morality that appears in various guises in Epicurus and Hobbes, that is suggested by a famous passage in Hume, and that achieves its clearest and most systematic articulation in the work of David Gauthier. ${ }^{5}$ According to morality as self-interested reciprocity, individuals have moral standing only by virtue of their strategic properties - their capacity to contribute positively to the welfare of others or to pose a threat to it. The general theme here is that morality is a kind of bargain among those who can affect each other's welfare, whether positively or negatively. It is fair to say that what many regard as one of the most progressive developments in morality - the 'social-embedding' (to use Kitcher's phrase) of the idea of human rights in domestic and international law-is a direct repudiation of morality as self-interested reciprocity. For after all, the core idea of human rights is generally understood to be that there are some rights - including very basic rights that give content to the idea of equal moral standing - that all human beings possess, not because of their strategic properties (their capacity to threaten or contribute to the well-being of others), but simply by virtue of their humanity. Historians of the modern human rights movement have marshaled impressive evidence to show that the salience of this idea and the effort to institutionalize it through international law were direct responses to the horrors wrought during World War II in the name of a fascist ideology that rejected the moral equality of all human individuals and asserted that the individual has worth only insofar as she contributes to the flourishing of the state or the nation. ${ }^{6}$ The Nazi's treatment of those they characterized as 'useless eaters' is the ultimate practical expression of the idea of morality as self-interested reciprocity.

Kitcher's omission of any discussion of the rejection of morality as selfinterested reciprocity as an instance of moral progress may not be a matter of chance. Consider, again, his view that our ancestors created and sociallyembedded norms to remedy altruism failures (rather than to avoid their costs in other ways) at the beginning of the ethical project because, in the then prevailing circumstances of equality of threat capacity, this was the only way or at least the best way to avoid the social costs of altruism failures. I have argued that Kitcher has not provided an account of how the ethical project could have transitioned from a situation in which the contingency of equal threat capacity ensured that the emerging norms would avoid social costs by remedying altruism failures (acknowledging the wishes and aspirations of all members of the group) rather than in some less morally wholesome way. The same point can now be rephrased: How, on Kitcher's view, could a project for normative guidance rooted in equal threat capacity have developed a coherent discourse that directly repudiates the idea that moral standing depends on threat capacity or any other strategic property? The answer, presumably, is that large numbers of

\footnotetext{
5 Buchanan 1990, 227-252. My main topic in this article is different conceptions of justice, but I also distinguish the more general view about the whole of morality.

6 The best single-volume case for this claim about the historical origins of the modern human rights movement is Morsink 1999, especially the first two chapters.
} 
human beings eventually came to develop new views about what confers moral standing and what does not. Nothing in Kitcher's description of the original function of ethics or his highly general remarks about the original function giving rise to new functions and engendering new desires tells us what we need to know to understand how this change could have come about. His answer cannot be that norms that achieve genuine remedies for altruism failures must repudiate morality as self-interested reciprocity because only such norms will take the wishes and aspirations of all seriously. The question, as I have already noted, is why, once the contingent constraint of equality of threat capacity no longer applies, we should expect moral norms to be fundamentally egalitarian, that is, to exclude strategic criteria for basic moral standing, such as threat capacity.

Perhaps Kitcher's omission of the modern human rights movement in his list of progressive developments stems from his failure to recognize the enormous gap between the sort of morality that was likely to develop in his original condition of equal threat capacity and the sort of morality that we now have. I suspect that this gap can only be bridged by an account that takes moral reasoning - and what might be called the open-ended normativity of the ethical-much more seriously than Kitcher does and, that when the story about moral reasoning is filled out, the idea that the present primary function of ethics is to remedy altruism failures will look quite implausible. For one thing, much of our moral reasoning proceeds on the basis of background assumptions about moral status. Questions about who has basic moral status are prior to questions about how to satisfy conflicting desires, because moral status determines whose desires even count.

\section{Kitcher's Positive Proposal: A Genuinely Cosmopolitan Morality}

According to Kitcher, the ethical project began as an exclusively intra-group activity - an attempt to remedy altruism failures among the members of a particular society that resulted in serious social costs to the members of that society. Near the end of his book, he identifies a high priority for the continuation of the ethical project: the development of a genuinely cosmopolitan morality that takes seriously the interests of all human beings, including perhaps especially the world's most desperately poor people $(E P, 311-312,374-84)$. Kitcher not only proposes much more globally egalitarian social norms and practices but also contends that in some sense this new progressive development can be seen as a natural continuation of the original ethical project.

That is a remarkable contention, given the vast distance between an ethical project geared toward remedying altruism failures in circumstances of equality among members of small, face-to-face groups and a genuinely cosmopolitan morality. How does Kitcher propose to traverse this distance? He tries to do so by pointing out that very early in the ethical project, when humans still lived in small groups, they developed trading relations with other small groups. Societies that did this well had to develop norms that 'acknowledged the wishes and 
aspirations' of out-group members. To the extent that good trading relations contributed to the well-being of groups, such norms took hold and proliferated. So far, so good; we can now see how the moral universe could be extended beyond the small group.

But notice that on Kitcher's account, this extension can only occur to the degree that the members of different groups can benefit each other (through trade). In other words, the ethical project is still limited to conferring moral standing on individuals by virtue of their strategic capacities, in this case, the capacity to contribute to the welfare of the members of other groups through trading with them. To the extent that he does anything to explain how a genuinely cosmopolitan morality could emerge from the humble origins of the ethical project, Kitcher suggests that the world's most affluent people must treat the worst-off in a much more egalitarian fashion because any alternative will involve unacceptable social costs. Thus he says that "[p]ragmatic naturalism [his normative stance] views us as facing a scaled-up version of the predicament of the original ethicists. The primary challenge stems from the need to address the sources of conflict [including] the pronounced inequalities of the contemporary world [...]." $(E P, 311)$

Note that his claim must be that to persist with our present grossly inegalitarian global order will result in unacceptable social costs to the affluent. In other words, if Kitcher is sticking to the characterization of the original function of the ethical project that I have argued he must employ if he is to provide an explanation of morality that begins with something nonmoral, he must be advancing the implausible claim that it is in the non-moral interest of the best off to undertake a radical divestiture of their wealth and power. He overlooks the fact that the best-off have shown remarkable skill in creating and sustaining a global order that does an excellent job of insulating themselves from the costs of inequality. They seem to be quite adept at avoiding the costs (to themselves) of their altruism failures, without remedying them. And, as I have argued, Kitcher has not shown why, as modern-day participants in the ethical project whose origins he claims to have illuminated, they should be concerned with remedying their altruism failures, rather than simply avoiding their costs.

The problem is that the resources of Kitcher's account of morality are not adequate to explain either the rationality or the likelihood of the emergence of a genuinely cosmopolitan morality. No appeal to equality of threat capacity or any other strategic property can demonstrate the rationality of global egalitarianism or explain why we should expect it to emerge from the ethical project as Kitcher has characterized it. If a much more egalitarian global order develops-and it is doubtful that it will-it is more likely to emerge from the growth of a way of thinking about morality that severs the conferral of moral standing from the possession of strategic capacities, something like the modern conception of human rights. But the development of that moral conception and its impressive though still inadequate 'social embedding' must remain mysterious on Kitcher's account of the ethical project.

If my arguments are sound, some of the central theses of The Ethical Project require, at the very least, substantial modification, and its explanation of the 
development of morality from its first appearance until the present will require much elaboration. Whether or not Kitcher agrees and takes up these tasks, he has written a book that everyone who thinks seriously about morality will have to take into account.

\section{Bibliography}

Buchanan, A. (1990), Justice as Reciprocity versus Subject-Centered Justice, in: Philosophy \& Public Affairs 19(3), 227-252

Edgerton, R. (1992), Sick Societies: Challenging the Myths of Primitive Harmony, Berkeley

Herdt, G. H. (1998) (ed.), Rituals of Manhood: Male Initiation in Papua New Guinea, New Brunswick

Morsink, H. (1999), The Universal Declaration of Human Rights: Origins, Drafting 8 Intent, Philadelphia

Schneewind, J. B. (1996), Introduction, in: Schneewind, J. B. (ed.), Giving: Western Ideas of Philanthropy, Bloomington

Sterelny, K. (2007), SNAFUS: An Evolutionary Perspective, in: Biological Theory $2(3), 317-328$ 